\title{
Dealing with Criminal Behavior: the Inaccuracy of the Quarantine Analogy
}

\author{
Sergei Levin ${ }^{1} \cdot$ Mirko Farina $^{2,3}$ (D) Andrea Lavazza ${ }^{4}$
}

Accepted: 19 August 2021 / Published online: 20 September 2021

(c) The Author(s), under exclusive licence to Springer Nature B.V. 2021

\begin{abstract}
Pereboom and Caruso propose the quarantine model as an alternative to existing models of criminal justice. They appeal to the established public health practice of quarantining people, which is believed to be effective and morally justified, to explain why -in criminal justice- it is also morally acceptable to detain wrongdoers, without assuming the existence of a retrospective moral responsibility. Wrongdoers in their model are treated as carriers of dangerous diseases and as such should be preventively detained (or rehabilitated) until they no longer pose a threat to society. Our main concern in this paper is that Pereboom and Caruso adopt an idiosyncratic meaning of quarantine regulations. We highlight a set of important disanalogies between their quarantine model and the quarantine regulations currently adopted in public health policies. More specifically, we argue that the similarities that Pereboom and Caruso propose to substantiate their analogy are not consistent-despite what they claim-with the regulations underlying quarantine as an epidemiological process. We also notice that certain quarantine procedures adopted in public health systems are inadequate to deal with criminal behaviors. On these grounds, we conclude that Pereboom and Caruso should not appeal to the quarantine analogy to substantiate their view, unless they address the issues and criticism we raise in this paper.
\end{abstract}

Keywords Retributivism · Quarantine · Isolation · Morality · Wrongdoers · Criminal justice $\cdot$ Pereboom

\section{Introduction}

A central objective of any theory of punishment is to specify and develop a model for dealing with criminal behavior that is both effective and morally justified. Derk Pereboom $(2001,2014 a, b)$ recently proposed a model (the quarantine model) that

Mirko Farina

farinamirko@gmail.com; mirko.farina@kcl.ac.uk; m.farina@innopolis.ru

Extended author information available on the last page of the article 
promises to be more humane and even more effective than alternative approaches (Hart, 1968; Moore, 2010; Murphy, 2007; Rawls, 1955; von Hirsch, 1992). According to Pereboom, we should treat dangerous wrongdoers as carriers of a contagious disease and therefore incapacitate them (that is, put them into quarantine) to prevent the occurrence of vicious crimes in society (Pereboom, 2001, 2014a, b). The incapacitation model developed by Pereboom has quickly become one of the cornerstones of contemporary debates on criminal justice (Corrado, 2016; 2019; Lemos, 2016; 2019; Focquaert, 2019). Gregg Caruso, in the attempt to refine Pereboom's account, recently reframed the incapacitation model originally proposed by Pereboom within the broader justificatory framework of public health ethics (Caruso, 2016), developing a non-retributive account of criminal behavior that prioritizes prevention, the proportion of sanctions, and social justice, which he called the publichealth quarantine model. Pereboom welcomed Caruso's integrations and additions (Pereboom, 2017, 2018, 2019) and together they co-authored a paper (Pereboom \& Caruso, 2018), and more recently edited a book (Shaw, Pereboom, and Caruso, 2019), where they explored the ramifications and practical implications of their nonretributive model of criminal justice for law and society.

Our major goal in this paper is to analyze whether the quarantine analogy Pereboom and Caruso propose is grounded and can be effectively used to substantiate their model. Focusing on the effectiveness of the analogy is not just a philological subtlety. In Pereboom's and Caruso's model the analogy with the public health practice of quarantining people plays a very important role, as it provides the moral justification for their model and guarantees its applicability. If it turns out that the analogy used is only a metaphor to illustrate their proposal, e.g. to make it clearer and more understandable to the general public, then Pereboom and Caruso would lose a strong argument required to deprive people of some of their basic civil rights (such as freedom of movement). Moreover, without the quarantine analogy Pereboom and Caruso would also lose the working example around which they can meaningfully frame their proposal. In other words, the analogy should be appropriate and suitable. Highlighting differences and inaccuracies in using the quarantine analogy is thus a way of making a motivated criticism to the overall model.

In Sect. 2, we introduce the quarantine model and explain how free will denial is used to justify this approach. In Sect. 3, we focus on the terminological inaccuracies that, in our view, affect the quarantine model. In Sect. 4, we demonstrate that quarantine regulations may include substantial voluntary and involuntary elements and argue that such measures could neither be effectively used in dealing with dangerous offenders nor be advocated with higher moral grounds. In Sect. 5, echoing and extending Smilansky's criticism (2011), we discuss how the quarantine model deals with wrongdoers (first time offenders), who do not pose a threat to society (and are therefore unlikely to repeat their crimes). We claim that the quarantine model does not have the resources to morally justify incapacitation and to deter wrongdoers from committing crimes. We discuss how Pereboom may reply to this objection (firstly raised by Smilansky); that is, by introducing financial sanctions and short prison terms that would act as general deterrence mechanisms. We counter Pereboom's reply by pointing out that he has no evidence to argue that financial sanctions and short prison terms would be an effective deterrence mechanism. 
Furthermore, we suggest that Pereboom's reply is an ad hoc response that contradicts the rationale of the quarantine model. We conclude, Sect. 6, by summarizing what we have achieved.

\section{Incapacitating the Wrongdoers}

An early version of a model prescribing the incapacitation -rather than the punishment of wrongdoers- was proposed by Karl Menninger (1968). Jeffrie Murphy (1979) criticized Menninger's model in the late '70 s. However, despite such criticism a refined and more sophisticated version of the incapacitation model of wrongdoers originally developed by Menninger resurfaced in recent years. This new version, renouncing moral responsibility in a basic desert sense, has been proposed by Derk Pereboom, (2001; 2014a, b) and subsequently articulated and defended by Caruso (2016). ${ }^{1}$

This version of the incapacitation model (known as the quarantine model) calls for the development -on humanitarian grounds- of an alternative, non-retributive system of criminal justice, that treats wrongdoers as not responsible for their crimes in the basic desert sense (Pereboom and Caruso 2018, 195), and attempts to rehabilitate offenders by detaining them in non-harsh conditions. Such a model is partially motivated by free-will skepticism (Pereboom, 2001; Strawson, 2010; Waller, 2015; Wegner, 2002); that is, proponents of this model believe that offenders shouldn't be punished or persecuted for the crimes they may have committed because: "what we do, and the way we are, is ultimately the result of factors beyond our control" (Pereboom \& Caruso, 2018, 195). Free will is often considered to be a grounding element of moral and legal responsibility and as such it is taken to provide justification for retributive punishment (Figdor \& Phelan, 2015; Pereboom, 2001; Pundik, 2016; Wood, 1938). Advocates of the quarantine model, in rejecting the existence of free will, thus propose a system to deal with criminal behavior that does not envisage freedom of choice for wrongdoers, and therefore implies the impossibility of holding them morally accountable for their actions in the basic desert sense.

One of the main tenets underlying the quarantine model is the idea that isolation -in non-harsh conditions- and subsequent rehabilitation of offenders is more humane than alternative forms of punishment, which are grounded on classical retributivism (Husak, 1992; White, 2011) hence on the principle of proportional justice, which states that the punishment of a certain crime should be in proportion to the severity of the crime itself (Deigh, 2014).

The quarantine model includes forms of preventative detention and ex post detention instead. The idea of preventative detention of dangerous subjects, which

\footnotetext{
1 Basic desert is defined by Pereboom as follows, 'For an agent to be morally responsible for an action in this sense is for it to be hers in such a way that she would deserve to be blamed if she understood that it was morally wrong, and she would deserve to be praised if she understood that it was morally exemplary. The desert at issue here is basic in the sense that the agent would deserve to be blamed or praised just because she has performed the action, given an understanding of its moral status, and not, for example, merely by virtue of consequentialist or contractualist considerations' (Pereboon 2014b, 2).
} 
Pereboom strongly endorses, rests on an analogy; namely the analogy with the process of quarantining infectious people. As we preventively isolate (for the interest of public health) potential carriers of a disease to prevent the spread of contagious illnesses, Pereboom claims, we ought to prevent potentially dangerous offenders to operate in society and cause harm to its citizens. This analogy, as noted above, is not only illustrative of a criminal strategy but it provides the justification for the model, as it demonstrates that society already uses the process of quarantining people for self-defense. Crucially -on Pereboom and Caruso's view- because that process is morally justified, then it reasonably follows that the preventive detention of wrongdoers ought also to be justified. In other words, the analogy with the process of quarantining people tells us the reason why we can quarantine wrongdoers by restricting some of their basic civil rights.

In order to establish this analogy, Pereboom identifies three major similarities between the process of quarantining people and the idea of preventative detention, which he endorses.

- The first similarity concerns the fact that in both cases (involving quarantining people and preventative detention) the subjects pose a serious threat to the individuals around them. Like carriers of diseases, who constantly run into the risk of infecting the people with whom they interact, future offenders are always on the verge of causing injuries and death to those whom they may encounter. Thus, for Pereboom, both offenders and disease carriers are united by the fact that they may well cause harm to the public.

- The second similarity revolves around the idea that both the criminal and the infected person cannot avoid doing harm to others, without the imposition of some restrictive measures, involving -for instance- the limitation of some of their civil liberties (e.g. freedom of movement and freedom of assembly).

- The third similarity, according to Pereboom, has to do with the fact that a wrongdoer, like a disease carrier, cannot be held responsible in a basic desert sense for the harm she may cause to others (Pereboom, 2014a).

On the grounds of these similarities, Pereboom claims that rather than imprisoning offenders and punishing them we ought to confine wrongdoers in rehabilitative centres and keep them in preventative detention until they are fully rehabilitated; that is, until they no longer pose a threat to public health and society. There are, in Pereboom's view, different levels of isolation or preventative detention. Crucially, however, these should all be based on two basic principles: (i). fairness of treatment and (ii). humanity. As Pereboom puts it: 'as less dangerous diseases justify only preventative measures less restrictive than quarantine, so less dangerous criminal tendencies justify only more moderate (e.g. just monitoring) restraints' (Pereboom, 2014a, 156). Furthermore, incapacitation revolves around the idea of well-being and rehabilitation. 'Just as fairness recommends that we seek to cure the diseased we quarantine, so fairness would counsel that we attempt to rehabilitate the criminals we detain' (Pereboom, 2014a, 156).

Pereboom's model has been much praised for his humanitarian take and has quickly become one of the cornerstones of contemporary debates in criminal 
justice (Tadros, 2011). Pereboom's model, however, has also received substantial criticism (Corrado, 2016; Lemos, 2016, 2019).

In recent years, the quarantine model has been defended and further refined by Gregg Caruso, who has framed the quarantine model originally formulated by Pereboom within a broader justificatory framework that draws from public health ethics. His account, known as the public health-quarantine model "provides a framework for justifying quarantine and criminal sanctions that is more humane than retributivism, and preferable to other non-retributive alternatives in that it prioritizes prevention and social justice' (Caruso 2016, 4).

Underlying the public health-quarantine model, much the same as for the quarantine model from which it is derived, there is the idea that retributive punishment is ethically and morally unjustifiable. This is due to the fact that both models share the assumption of free will skepticism, which implies that people shouldn't be held morally responsible for their own actions in the basic desert sense. Another principle that the two models share is the principle of least infringement, which is formulated to guarantee that sanctions will always be proportionate to the actual danger posed by a given individual ((i). fairness of treatment) and will never be unjustified-too harsh or too cruel ((ii). humanity).

However, the public health ethics model much more than the quarantine model emphasizes the need to take the necessary steps to prevent quarantining from occurring in the first place, as quarantine (hence deprivation of people's basic liberties) is seen as the least possible measure available to the criminal justice system. This means that, on the one hand, this model aims at minimizing potentially harmful actions against citizens (thus protecting the society and the individual in it). On the other hand, though, this model also invites us to shift the focus of our attention from the dimension of punishment and retribution to the dimension of care and prevention, asking us to identify and possibly tackle, hence change the socio-cultural (environmental) conditions that trigger criminal behaviours, which Caruso calls the systemic causes of crimes (or determinants of criminal behavior). Caruso's model can therefore be praised for his attempts to remedy social and economic inequalities (such as racism, sexism, poverty, gender discrimination, and other systemic disadvantages), which are well-known triggering factors for crimes.

Thus, summarizing the views at stake here we can say that both Pereboom and Caruso think that the right to harm in self-defense and defense of society at best only justifies temporarily incapacitating wrongdoers with the minimum harm required (punishment is seen as unnecessary cruel). Their models also focus on the well-being of offenders and strive to guarantee their long-term rehabilitation. Caruso's variation of the quarantine model also emphasizes the issue of social justice, demanding us to take actions against the socio-cultural determinants of criminal behavior. Despite this difference in emphasis, and given the similarities between Pereboom and Caruso's views, for simplicity, in what follows we discuss their accounts as one, under the label quarantine model. 


\section{Quarantine and Isolation}

As we have seen above, Pereboom and Caruso suggest to abandon the existing criminal justice system, which-on their view-is morally unjustified and propose the adoption of quarantine measures used in public health policies to deal with criminal behaviors. We believe that Pereboom and Caruso (and some of their critics) paid little attention to how quarantine regulations are actually applied in public health policies. On these grounds, while praising their humanitarian approach, we show that their analogy is only partially justified and therefore that it can be questioned.

Quarantine is an old tool used to prevent the spread of dangerous diseases. The term quarantine, which is derived from the Latin quadragina and the Italian quaranta, was used in the 14th-century to prevent the plague from spreading. To control disease transmission, ships coming into the harbor, were required to remain in the harbor for 40 days before being allowed to disembark (Knobler et al., 2004). Quarantine has since then been used as an effective tool for countering disease transmission by governments and institutions around the world.

Nowadays, the general public and mass media often use the term quarantine as a synonym of another term, isolation, and we believe that Pereboom and Caruso do this as well (more on this below). However, quarantine and isolation are very different public health tools. They are both designed to control and possibly stop the spread of a disease; yet, they also have their specific aims and means of implementation. Below, we present the definitions for these terms (our source is the US Centers for Disease Control and Prevention):

- 'Isolation separates sick people with a contagious disease from people who are not sick';

- 'Quarantine separates and restricts the movement of people who were exposed to a contagious disease to see if they become sick' (CDC, 2020).

The Dictionary of Epidemiology (Porta et al., 2014) illustrates the legal and ethical implications of quarantine and isolation:

- 'The clinical distinction between isolation and quarantine is that isolation is the procedure for persons already sick, whereas quarantine is often applied to (apparently) healthy contacts. This has legal and ethical implications if apparently healthy persons must submit to restrictions upon their freedom to move at large in society' (235).

We believe that the meaning of these terms does not match the usage that Pereboom and Caruso-following Schoeman (1979)_-do of them in their research. Pereboom writes: "When a person with cholera is quarantined, she is typically made to experience deprivation she does not deserve" $(2001,177)$, and: "many carriers of dangerous diseases are not responsible in this or any sense for having contracted these diseases. We generally agree that it is sometimes permissible 
to quarantine them nevertheless" and "we seek to cure the diseased we quarantine" $(2014,156)$. Caruso echoes this reasoning in one of his recent books $(2017$, 17). Thus, it seems that Pereboom and Caruso think that quarantine is a tool that should be used to deal with carriers of contagious diseases.

On these grounds, Pereboom and Caruso assume that wrongdoers are analogous to contagious disease carriers and as such may need treatment. However, if this is the case, then such people should be isolated, not quarantined. People under quarantine are not necessary carriers of infectious diseases; they are just suspected carriers and many of them do not need any treatment unless it turns out, at a later stage, that they have been infected. If we know that a person is infected then she no longer requires being quarantined; she needs to be isolated.

The confusion between quarantine and isolation is not only a terminological squabble; it raises an important practical question: at which stage of the investigation or a legal procedure should we start treating a wrongdoer as a carrier of a contagious disease? Pereboom and Caruso provide no straightforward answer to this pressing question. They certainly talk about wrongdoers and dangerous criminals; however, they never fully explain how their guilt (in the sense of material responsibility, see below) can be established (Caruso, 2017; Pereboom, 2014a, b; Pereboom \& Caruso, 2018). Yet, in any criminal justice system, a person has to go through various stages before she is declared guilty. Criminal laws and investigation procedures differ from country to country, but generally, it is possible to distinguish between at least two stages in determining whether the person is a wrongdoer. In the first stage, the person is suspected and/or charged with the crime, but it is not yet clear whether she really committed the crime for which she has been charged. In the second stage, a judicial procedure is implemented so as to establish whether the person charged for the crime in the first stage should be convicted; that is, through the adoption of such a procedure it is determined, beyond a reasonable doubt, whether the person is guilty.

Pereboom and Caruso may preliminarily object that the notion of guilt is misplaced and should be abolished. The notion of guilt consists of, at least, two different elements. The first element inherits the factual discovery of whether the alleged wrongdoer committed a wrongful action. The second concerns deciding whether that individual is blameworthy for the wrongful action she has committed. This second element does not exist in the quarantine model because people are believed to be unfree, and therefore ought not be held responsible for their actions in the basic desert sense (Pereboom \& Caruso, 2018, 202). Pereboom and Caruso may claim that in their model there is no point in establishing guilt in the same sense as we do it here. However, even if we adopt their perspective, which is grounded on free will skepticism, we will still need to establish whether a person has done something wrong. This is because the offense is a reliable and -perhaps- the most common indicator of dangerousness. For example, we can reasonably conclude that the person who murdered 5 people is dangerous. However, the person who was wrongfully accused of killing 5 people is not dangerous, unless we have other reasons to think so. Pereboom and Caruso allow the incapacitation of dangerous people who have not yet committed a crime (Pereboom and Caruso 2018, 215). However, they are cautious about such cases and the majority of the examples they use to illustrate 
their model are about the dangerous wrongdoers who committed an offense and are considered dangerous because of that. We keep in mind that an individual can be dangerous without committing any crime, but we here focus on the cases where the dangerousness is derived from the gravity of the crime.

Pereboom and Caruso could also object that the difference we specified above between quarantine and isolation is practically meaningless, because both suspected carriers and carriers are ultimately detained. So, it does not matter whether you call that process isolation or quarantine. However, quarantine and isolation differ significantly with respect to the way in which we treat the people affected by them in epidemiological contexts. Individuals are quarantined until their diagnosis is known. It is only after the symptoms have manifested or a positive test is returned that people start taking medicines for their disease, never before. If the individuals turn out to be healthy, the quarantine ends, and further medical procedures are unnecessary. The same logic, we believe, should be applied to people suspected/accused of wrongdoing in the quarantine model, if we want the analogy to hold at least. It seems to us though that the incapacitation or rehabilitation of those individuals who did not commit any crime is utterly redundant.

Therefore, even without the implementation of the notion of guilt (with all its moral presuppositions) the quarantine model still needs to include a reliable technical procedure to establish whether someone committed an offense. In addition, it seems to us that advocates of the quarantine model (such as Pereboom and Caruso) would need to make clear at what stage exactly we should treat wrongdoers as carriers of a contagious disease. In any case, it should be stressed that in the incapacitation model proposed by Pereboom and Caruso the analogy is not a mere rhetorical tool. It plays a crucially important argumentative and moral role in the justification of the specific coercive treatment that wrongdoers and potentially dangerous people are subjected to. Thus, insofar as the analogy does not hold, the entire line of justification provided by Pereboom and Caruso to support their quarantine model should be amended accordingly.

Pereboom and Caruso may perhaps rejoice by including the 'dangerous criminals' in the group of convicted wrongdoers. For example, if we know that a person robbed and/or murdered someone, then we know that she is dangerous. Therefore, we ought to incapacitate her. In this sense, the analogy proposed by Pereboom and Caruso is similar to the process of isolation but not to the process of quarantining people. This is because isolation, as we have seen above, applies to people who are carriers of a contagious disease (hence they are infected), whereas quarantine is reserved for those who are suspected to be carriers of a contagious disease (hence are not necessarily infected). However, convicted wrongdoers are not individuals, who we suspect are offenders (therefore we can quarantine); convicted wrongdoers are individuals that the criminal justice system believes, beyond a reasonable doubt, to have committed a crime (therefore, they are individuals that should be isolated from society).

In other words, the quarantine analogy better suits those who have been charged with a crime, but haven't been convicted (that is, their guilt has not yet been established beyond a reasonable doubt). This is because some criminal justice operatives decided that there are reasonable indications (proof gathered by 
the police or other actors during the legal investigations) that make us think that these people are potentially dangerous individuals. Of course, people who have been charged with a crime may not be dangerous criminals at all, as the accusations may be false, but for general public safety, it may be possible to justify their arrest without assuming their guilt (this is not necessarily our position, but it is indeed a point of view that someone could defend here).

There are nuanced differences between treating a dangerous convicted criminal as a carrier of contagious disease and treating the people who are charged with crimes as we treat those who were directly exposed to a contagious disease. First (as we noted above), people who are charged with a crime are not required to go through a correction or a rehabilitation program, as they are presumed innocent until proven guilty (or until believed to have committed a crime, if our reader finds the word guilt not appropriate). Second, the time needed to establish 'guilt' is typically much shorter than the length of the sentences dangerous criminals may receive. Quarantine for those charged with a crime is only a temporary solution that is not designed for incapacitating and rehabilitating dangerous criminals after their guilt (in the sense of material responsibility) has been established. It follows that the quarantine analogy that Pereboom and Caruso propose may be appropriate to deal with charged individuals; however, it does not seem applicable to convicted criminals. Thus, we believe that Pereboom and Caruso should clarify their position with respect to this point. Before we proceed any further, another technical clarification seems needed. Pereboom and Caruso use the term dangerous disease as a synonym of serious communicable disease. As they put it:

'plainly, many carriers of dangerous diseases are not responsible in this or in any other sense for having contracted these diseases. Yet we generally agree that it is sometimes permissible to quarantine them, and the justification for doing so is the right to self-protection and the prevention of harm to others. For similar justificatory reasons, we argue, even if a dangerous criminal is not morally responsible for his crimes in the basic desert sense (perhaps because no one is ever in this way morally responsible) it could be as legitimate to preventatively detain him as to quarantine the nonresponsible carrier of a serious communicable disease'. [emphasis added] (Pereboom \& Caruso, 2018, 205).

However, the most accurate technical expression to refer to the process of quarantining people in the sphere of public health should be: 'contagious or communicable disease', not 'dangerous disease'. For example, anthrax is a very dangerous disease; yet it cannot spread from person to person directly, therefore quarantine is not justified if we suspect that someone was exposed to anthrax (Upshur, 2003). We believe that this terminological confusion should be fixed in order to show that the proposed analogy is based on the danger that criminals or carriers of a contagious disease are posing to other people. Thus, if Pereboom and Caruso want to keep the quarantine analogy, it seems to us that they need to do some clarificatory work. In particular, they need to explain whether they have in mind quarantine or isolation, or both, when they propose to adopt the analogy. Likewise, they should be more precise when they use expressions like 'contagious or communicable disease' or 'dangerous disease'. 
A skeptical reader may object here that it is possible to say that the word quarantine is used metaphorically and quite loosely. For this reason, the analogy doesn't need to be very close for the idea that is presented to establish. This is a legitimate objection to raise; however, it seems to us that talking of isolation is more suitable for the proposed analogy because isolation applies to carriers of contagious diseases, and we see no reason to use in such circumstances the less appropriate term 'quarantine'. In any case, if Pereboom and Caruso want to say that the quarantine analogy is a metaphor that is more accessible to the general public, then they need to say explicitly that by quarantine they meant the popular image of quarantine and not the medical process, which is regulated by specific epidemiological protocols. Once again, the metaphor serves as a justificatory argument, and, therefore, it cannot be blur, loose, or vague, unless one is prepared to renounce its specific role in the quarantine model.

\section{Quarantine: Voluntary or Involuntary?}

Having shown some of the problems affecting the quarantine analogy, we next turn to analyze whether voluntary and involuntary means of imposing quarantine and isolation may be used as tools for dealing with dangerous criminals. Both quarantine and isolation may be implemented on a voluntary or involuntary basis, with the preference for the former: "from a modern public health perspective, the best way to implement isolation and quarantine is through voluntary means, although in some cases compulsory means may be required" (Gostin, Gravely, Shakman, Markel, \& Cetron, 2004, 83). Voluntary quarantine is a recommendation for staying at home for those who may have been exposed to the disease. The recommendation means that people are advised to follow certain protocols by goodwill and not out of fear of sanctions. The medical or political authorities may ask people, who may be carriers of infectious diseases, to stay at home or to stay in special facilities (e.g. infective centers) to protect society. Many people may voluntarily follow such recommendations. The instruction to stay away from others for those who were exposed to a contagious disease makes perfect sense (it is rational) with or without the prospects of penalties for breaking quarantine or isolation.

In the recent COVID-19 pandemic some quarantine measures were compulsory, but there were also many recommendations for voluntary quarantine. Here is one of such recommendations, endorsed by the French government:

'French nationals or permanent residents in France may, however, enjoy continued access to French territory, as may certain specific categories of people set out on the website of the Ministry of the Interior. In return, people are nevertheless asked to act responsibly by placing themselves in voluntary quarantine. On their arrival on French territory, those admitted who arrive from outside the European area will be provided with information about the conditions under which the voluntary quarantine can be carried out at their chosen address or, where applicable, in appropriate 
accommodation. Travellers are called upon to be civic-minded and demonstrate a sense of responsibility in putting this health precaution into practice' (Ministry for Europe and Foreign Affairs, 2020²).

There is a rationale behind voluntary compliance with such recommendations. People agree to limit their contact with the external world, as they have no interest in spreading the disease. This applies both to quarantine and isolation. In the case of quarantine, people who are suspected of being ill (e.g. because they came into contact with an infected individual), can voluntarily stay at home to protect others from the potential threat they may carry. Likewise, other people may voluntarily want to reduce their possible exposure to a disease they may not have at that particular moment in time. However, in the case of isolation, infected people know about their illness and they have a certain altruistic incentive to stay away from other people. Some people may have personal reasons to break the regulations (work, entertainment, etc.), but those reasons are external to the disease itself. In other words, even if someone breaks isolation it is very unlikely that she is doing it to intentionally spread the disease. This makes both voluntary quarantine and isolation quite effective tools for regulating public health policies.

It could also be the case that the majority of people follow compulsory quarantine restrictions out of goodwill, not necessarily because of fear of sanctions. For example, in 2003 during the SARS outbreak, the city of Toronto used both quarantine and isolation measures to fight the epidemic. 13,374 people were placed under quarantine. The overall degree of cooperation and compliance was extremely high with only 27 people found not to comply with quarantine directives (Basrur, Yaffe, $\&$ Henry, 2004, 23). Some cases of non-compliance likely went undetected, but this example clearly shows that the public at large may accept restrictions (such as quarantine) when needed. Similar considerations apply to the current COVID-19 pandemic where many people are ready to follow recommendations for quarantine and isolation. However, while we believe that voluntary quarantine and isolation work well as tools for regulating public health policies, we do not think they may be effectively applied to deal with dangerous offenders in all significant matters.

Pereboom and Caruso claim that the process of preventive detention they advocate for dealing with potentially dangerous wrongdoers is analogous to the process of quarantine. However, they do not discuss the difference between voluntary and compulsory epidemiological measures. In the previous section, we noted the difference between quarantine and isolation. Keeping this important difference in mind we now distinguish four different procedures: (i). voluntary quarantine, (ii). involuntary quarantine, (iii). voluntary isolation, and (iv). involuntary isolation. Next, we will analyze whether Pereboom and Caruso may incorporate each of these procedures in their model and what consequence does this potential incorporation may bear on their account.

\footnotetext{
${ }^{2}$ Ministry for Europe and Foreign Affairs. Travel Restrictions and Implementation of Public Health Measures at Borders. https://www.diplomatie.gouv.fr/en/coming-to-france/coronavirus-advice-for-forei gn-nationals-in-france/coronavirus-statements/article/travel-restrictions-and-implementation-of-publichealth-measures-at-borders (last accessed Oct. 2020).
} 
Voluntary quarantine does not really fit Pereboom and Caruso's approach because it is either not needed or it should be instead called isolation. Individuals in medical quarantine (voluntary and involuntary) do not know whether they contracted the contagious disease and whether they are dangerous. So, they may decide to limit their contacts and stay at home to protect others. On the contrary, people practically almost always know whether they committed a serious offense (murder, robbery, violent sexual assault, etc.) or have an intention to do so. It is as if people all the time had the reliable test at hand to tell whether they may carry any virus. If it were the case, all the people under medical quarantine would either return to normal life (got negative test result) or switch to isolation (positive test result). People who know that they did not commit any crime and have no inclination to do so have no reasons to voluntarily quarantine themselves. Those who know about their serious offenses most likely do not aim to promote safety, so they would not stay in voluntary quarantine. In an extraordinary case, an offender may want to separate herself because she knows she is dangerous. This, however, would be a case of voluntary isolation, not of quarantine determined by real danger.

Involuntary quarantine is a situation when officials suspect someone to be a dangerous offender and detain the person for the time necessary to complete the investigation. The epistemic difference between criminal and medical quarantine is that suspected carriers of contagious diseases do not know whether they are dangerous, while people under criminal quarantine would nearly always be conscious of whether they committed any crime. In general, this procedure seems to work within the quarantine model, and it would not differ much from the current criminal justice practices.

However, let's now turn our attention to the cases concerning voluntary and involuntary isolation. Voluntary isolation would not be effective. Could we possibly ask dangerous offenders to isolate themselves, so they would not commit new crimes? Hardly so. Pereboom and Caruso reserved isolation from society as a last resort measure only for the most dangerous offenders (Pereboom \& Caruso, 2018, 205). Dangerous offenders, most likely, would not be responsive to requests to stay away from potential victims. It seems pointless to ask robbers, murders, sex offenders, etc. to separate themselves from other people for the sake of public safety. Criminals may have egoistic reasons to commit new crimes, unlike carriers of dangerous diseases, who typically do not have reasons to spread it. If dangerous criminals wanted to protect others, they would refrain from committing crimes in the first place.

Involuntary isolation is what probably Pereboom and Caruso mean by quarantine in their model. Apart from the terminological confusion and practical issues we pointed out in the previous section, there is one more underlying moral implication that distinguishes involuntary medical and involuntary criminal isolation. People in medical isolation are there because they have a dangerous contagious disease. The chances that nowadays doctors wrongly put a person in isolation for a long time are negligible. This gives even involuntary medical isolation a high moral ground. In other words, we do not put people in medical isolation by mistake.

We believe that Pereboom and Caruso implicitly rely on the high moral status offered by medical isolation when they advocate criminal isolation in their model. However, criminal isolation morally differs from medical isolation. This is because, 
as we know it, in criminal justice systems a considerable number of people are always convicted for the crimes they did not commit. Yet, Pereboom and Caruso provide no ground to persuade us that their model would solve the problem of wrongful convictions. This implies (and this is a real possibility) that some innocent (in the sense of material responsibility) and not dangerous people would inevitably end up in involuntary criminal isolation. Therefore involuntary criminal isolation does not share the same moral and ethical grounds with involuntary medical isolation.

In their model, Pereboom and Caruso seem to be not considering the difference between voluntary and involuntary measures as well as the differences between quarantine and isolation. They may, once again, reply that all these epidemiological distinctions are too technical and that the disagreement comes down to just a verbal dispute or squabble. However, as we showed, the analysis of these distinctions reveals important practical and moral mismatches or disanalogies between the quarantine model and the epidemiological process from which the model is derived.

In any case, being charitable to Pereboom and Caruso, we must note that even purely terminological corrections would be extremely helpful to perfect and refine their model. Due to the COVID-19 crisis, many people were under voluntary quarantine; as a result, the public can think that Pereboom and Caruso suggest similar measures to be applied for dangerous offenders. Hence, it seems that if Pereboom and Caruso want to keep their analogy, then they need to better explain how voluntary quarantine or isolation measures may fit their model of incapacitation of wrongdoers. If the authors cannot explain or accommodate the distinctions we explained above, then they should rephrase or change their analogy, which is crucial for the establishment of their model.

\section{Revenge, Desertion, and Deterrence}

Having analyzed how the voluntary/involuntary elements underlying quarantine regulations fail to be an effective tool for dealing with criminal behaviors, we next consider another related weakness of Pereboom's and Caruso's approach. We argue that the quarantine model might not be that effective and efficient in deterring crimes from one-time offenders. In other words, we claim that the quarantine model won't be able to prevent certain types of wrongdoers from committing offences in the same way in which the process of quarantining people does prevent the contagion from spreading further.

Saul Smilansky argued that quarantine like measures would fail to efficiently deter criminal behaviors. In particular, he claimed that abolishing punishment and replacing it with detention and rehabilitation with high standards of living for wrongdoers would drastically hinder the current deterrence effect of criminal justice policies (Smilansky, 2011, 2017). In other words, Smilansky argued that the quarantine model cannot provide enough deterrence for potential offenders, who do not pose a significant threat to society (as they are unlikely to reiterate the crime they committed). He writes: 
'... an otherwise law-abiding and moral man, who quite reasonably hates his ill wife (who abused him throughout their marriage), deprives her of her medication in order to shorten her life. Or, children who tamper with a medical device in order to hasten the death of a very wealthy but obnoxious parent from whom they will inherit. Yet the public health-quarantine model may well not yield the required result. All the man wanted was to get rid of his wife, and there is no reason to think that he will pose any social danger once this unique problem is solved for him. Likewise, the children have always been normatively well behaved, and will continue to be so; it was just extreme financial pressures that led them to do it, and those pressures have now been permanently relieved through the inheritance' (Smilansky, 2017, 598).

Thus, in Smilanksy's view-which we endorse here - the quarantine model does not offer any resource to incapacitate wrongdoers. In other words, if the quarantine model was to be implemented in the real world, then potential criminals would know about its principles and applicability and would be in a position to know how to commit a crime without fearing the unpleasant consequences normally attached to it.

Pereboom's answer to this objection is two-fold. He notices that the cases that Smilansky describes would be extremely rare in the real world; however, he concedes that his model needs to allow financial penalties and limited incarceration for the sake of general deterrence. In other words, Pereboom claims that non-dangerous criminals may be fined or incarcerated if that promotes general deterrence and does not significantly harm them (Pereboom, 2017, 2018).

Both answers given by Pereboom deserve attention. While Pereboom acknowledges the problem, it seems to us that he tends to downplay it (such cases, he says, are 'extremely rare' in the real world). The rarity of the cases, in his view, allows us to treat them as exceptional cases, without sacrificing the spirit of the quarantine model. However, whether the cases Smilansky proposes, as Pereboom suggests, are extremely rare in the real world is a question that is open for discussion. Next, contra Pereboom, we try to show that such cases are in fact not so rare. Thus, we expand on Smilansky's criticism. There are, we believe, at least two types of crimes, which have not been looked at in the literature, for which criminals may not pose a future danger to society, in the sense envisaged by Pereboom and Caruso. These crimes are: (i). desertion from the military and (ii). violent revenge.

Military desertion can be defined as the abandonment of a duty or post without permission with the intent to remain away from the military permanently. The punishment for desertion in modern armies varies depending on the circumstances, but if desertion is committed during wartime the punishment often involves death penalty or life-imprisonment ("Article 85 (10 U.S.C. 885)-Desertion," 2019, IV-10). Desertion is not an imaginary or an unusual crime. It happens often during wartime and can pose a national threat to the country affected by the desertion.

Some deserters leave their posts or duty out of fear, some do that due to low morale, others due to the conditions of service, some may have ideological or personal reasons to desert (Bushnell, 2017; Iacobelli, 2013; Woodbury, 1921). Improving conditions of service, persuading soldiers that they fight for the right cause, increasing salary, etc. may help to reduce the number of deserters; however, some 
soldiers -especially during wartime-may desert anyway. In the face of death, injuries, and suffering - understandably perhaps- some soldiers would wish to desert. Some deserters may commit other crimes after they flee the army, some may not. What is important for the purpose of our discussion is that the act of deserting doesn't by itself indicate that the deserter is violent or has an intent to hurt other people. After all, many deserters just wish to run away from violence and suffering. Thus, deserters qua deserters are not necessarily dangerous for others.

Violent revenge is another example of a crime, whose perpetrators need not be dangerous for society after the crime is committed. Revenge is not a specific crime, but it is a well-recognized motive for crime and violence. Below we discuss a real story of revenge killing, involving a Russian former architect (Vitaly Kaloev) who killed an air traffic controller Peter Nielsen, in 2004. Kaloev held Nielsen solely responsible for the death of his family, which was aboard of the Bashkirian Airlines Flight 2937, which collided with DHL Flight 611 over Überlingen, Germany, on 1 July 2002. Kaloev was convicted of the premeditated killing of Peter Nielsen and sentenced to eight years in prison. However, after two years in prison, Kaloev was released. ${ }^{3}$

Before the tragic events, Kaloev had no criminal history and was a reputable architect. After the release, he never committed another crime. He worked as a deputy minister of construction of North Ossetia for eight years (2008-2016), prior to retirement. It seems that Kaloev had the intention to kill only one person (Peter Nielsen), who - in his opinion- was solely responsible for the death of his family and of the $60+$ passengers, who were on board of the passenger jet that crashed. After he fulfilled his goal (and took his revenge) he had no intention to cause trouble to anyone else. Kaloev's case is a perfect real-life example of how a law-abiding citizen may commit a vicious crime without subsequently posing a threat to society. Many cases similar to Kaloev's case do exist in the real world (the reader may think about Gjakmarrija) (Mustafa \& Young, 2008) -the Albanian blood feud- that requires to commit murder in order to salvage the honor questioned by an earlier killing (for more details see ${ }^{4}$. We believe, pace Pereboom and Caruso, that any model designed to deal with criminal behavior must provide an adequate answer for such real-life scenarios. Crucially, it seems to us that the quarantine model does not.

In the cases we discussed above (desertion and violent revenge) the quarantine analogy does not seem enough to justify incapacitation. The quarantine model justifies incapacitating the criminally dangerous with the minimum harm required for adequate protection (Pereboom \& Caruso, 2018, 207). Deserters and certain avengers - provided their thirst for revenge has been quenched-do not pose any significant danger to the public or to society; thus, society does not need to be protected, hence, such people should be set free. The problem of general deterrence arises in

\footnotetext{
${ }^{3}$ Nick Paton Walsh, Nothing left to lose: grief-crazed murder suspect haunted by family's air deaths, THE GUARDIAN (Feb. 27, 2004, 8:40 PM), https://www.theguardian.com/world/2004/feb/28/russia. lukeharding.

${ }^{4}$ Vincenzo Mattei, Albania: The dark shadow of tradition and blood feuds, ALJAZEERA (May 14, 2016), https://www.aljazeera.com/features/2016/5/14/albania-the-dark-shadow-of-tradition-and-bloodfeuds Last accessed August 2021.
} 
this context nonetheless. Wrongdoers, both in Smilansky's examples and in our case studies, may know that according to the quarantine model no punishment would be assigned to their crimes if they are deemed not to be dangerous for society, as such they may well be inclined to commit a crime, which they wouldn't otherwise be willing to commit. This is not the case where the punishment would be assuaged, but a case where there would be a complete lack of punishment altogether. Such offenders, according to the quarantine model, could commit those crimes without fearing their consequences (e.g. incarceration).

Pereboom acknowledges the problem and argues that we should implement small fines and minimum prison sentences to account for the cases proposed by Smilansky. The goal of such punitive sanctions is to provide general deterrence for potential offenders. Pereboom, following Daniel Farrell, distinguishes between special deterrence and general deterrence (Farrell, 1985). Special deterrence is a punishment aimed at preventing the particular criminal, specifically, from engaging in future criminal behavior, whereas general deterrence is a punishment aimed at preventing agents other than the targeted criminal from committing the crime.

Pereboom believes that fines and short prison terms would be a sufficient deterrent for the greedy relatives and uxoricide discussed by Smilansky (Pereboom, 2017). However, we believe that it is unlikely that such measures would be an effective deterrent for deserters during wartime and for those who lost their dear ones and seek revenge. Deserters may reasonably fear the enemy's fire much more than a short-term prison sentence or a fine. Likewise, it is hard to deter with relatively weak penalties people who decided to take justice into their own hands. Even if Pereboom could still reply that such preventative measures (fines and short prison terms) may be effective (it is not clear how, but let's take this possibility for granted), there is a further conceptual problem that seems to affect Pereboom's response, which - in turn- seems to cast substantial doubts on the quarantine model.

Pereboom argued that fines and short-term prison terms are justified measures for the sake of general deterrence. This, we believe, looks like an ad hoc response that contradicts the spirit of the quarantine model. The quarantine analogy is presented with a set of problematic counterexamples, which threatens its validity, and Pereboom suggests additional (semi-retributivist) measures that lie outside of the scope of the original model he developed. In other words, if some retributivist or quasi-retibutivist elements (such as fine and short-term prison terms, which are evidently retributivist elements in nature according to Pereboom's premises) need to be included in the model for it to be able to deal with some of its shorcomings; then -it follows- the model is not a real alternative to other current penal systems and other justification theories of punishments.

Quarantine regulations do not justify, for the sake of general deterrence, sanctions for being infected or being exposed to infected individuals. Quarantine, as a medical procedure, has not been designed as a form of punishment; rather it has been formulated as an epidemiological measure to prevent infections from spreading. In addition, the process of quarantining people is never applied as a measure of deterrence (Upshur, 2002, 2003; Spitale, 2003). There is no need to implement some forms of punishment in order to deter people from contracting a disease. People, in normal circumstances, don't get any profits from being exposed to infectious diseases and 
thus they try to avoid catching them, if possible. In other words, quarantine doesn't serve the purpose of deterrence as the prospect of getting infected represents a significant deterrence by itself. Criminals, in contrast, may profit from offenses and sometimes deliberately decide to commit crimes either for immediate returns (e.g. robbery) or for some 'vicious' pleasure that the crime would deliver to them (e.g. sex offense). People have reasons to become criminals, and deterrence is one of the ways to stop them. Thus, if Pereboom is ready to implement semi-retributivist penalties (such as fines or short-term prison) in his model, it seems to us that he is diverting from its original humanitarian purpose. This conceptual problem, in our view, affects Pereboom and Caruso's account and we believe it constitutes a potential counter-argument to it.

To save the quarantine analogy Pereboom and Caruso may try to draw an analogy with the punishment that is inflicted to those who break quarantine. However, those people are punished not because they have become (potentially) dangerous. Punishment is inflicted upon them for the intentional violation of an enforced epidemiological protocol. Wrongdoers (such as army deserters and avengers) should not be preventively detained (placed in the quarantine), as they pose no genuine threat to society. So, we can't punish them for breaking 'quarantine', as they should not be under quarantine in the first place. Again, it follows, that if Pereboom and Caruso introduce sanctions for the sake of general deterrence, the resulting model would substantially depart from the quarantine analogy and would start looking as a hybrid model, somehow analogous (perhaps just more lenient) to models of criminal justice currently adopted in many countries.

\section{Conclusion}

In this paper, we highlighted three issues with Pereboom and Caruso's model that are related with the appropriateness and adequacy of the quarantine analogy but also with its potential applicability. Firstly, there is a terminological confusion between quarantine and isolation affecting Pereboom and Caruso's proposal. The word quarantine does not denote a neutral concept, quite the opposite; it denotes a medical term with a precise epidemiological meaning and whether or not the quarantine analogy holds it depends on the meaning of this term. We demonstrated that Pereboom and Caruso do not pay enough attention to the medical definition of this term and that may affect the validity of their analogy. Secondly, we showed that voluntary quarantine proves to be a crucial element of disruption in the analogy proposed by Pereboom and Caruso. Whereas people may follow quarantine indications under certain conditions (e.g. a pandemic); it is unlikely that wrongdoers will be responsive to such indications. Thirdly, there is a further issue; namely deterrence potentially affecting Pereboom and Caruso's account. We showed that the quarantine model won't be able to prevent one-time offenders from committing crimes in the same way in which quarantining people does prevent the spread of a virus. Pereboom concedes that financial penalties and short-term prison terms could be used for the sake of general deterrence; however, the introduction of these measures in 
his model seems problematic and not compatible with the humanitarian spirit of the original quarantine proposal.

If the arguments we presented in this paper are sound we conclude that Pereboom and Caruso ought to refine the quarantine analogy as well as their quarantine model (as it is firmly grounded on that analogy) or -at least- address the challenges we raised here. Public health regulations and the quarantine model do not need to be identical in all respects for the analogy to hold; however, there should be crucial similarities between them. We believe to have shown that the model developed by Pereboom and Caruso lacks such crucial similarities for a meaningful analogy to be substantiated.

Acknowledgements This work was carried out under the project 'Applied ethics', financed by the HSE university.

\section{References}

Article 85 (10 U.S.C. 885)—Desertion. (2019). In Joint Service Committee on Military Justice. Fort Belvoir, Virginia: United States Army Publishing Directorate.

Basrur, S.V., Yaffe, B., \& Henry, B. (2004). SARS: A local public health perspective. Canadian Journal of Public Health, 95, 22-24. https://doi.org/10.1007/BF03403628

Bushnell, J. (2017). Russian Peasants and Soldiers during World War I: Home and Front Interacting: Guest Editor's Introduction. Russian Studies in History, 56, 65-72.

Caruso, G. D. (2016). Free will skepticism and criminal behavior: a public health-quarantine model. Southwest Philosophy Review, 32.

Caruso, G. D. (2017). Public Health and Safety: The Social Determinants of Health and Criminal Behavior. UK: ResearchersLinks Books.

Deigh, J. (2014). Punishment and Proportionality. Criminal Justice Ethics, 33, 185-199.

Farrell, D. M. (1985). The justification of general deterrence. The Philosophical Review, 94, 367-394. JSTOR.

Figdor, C., \& Phelan, M. (2015). Is Free Will Necessary for Moral Responsibility?: A Case for Rethinking Their Relationship and the Design of Experimental Studies in Moral Psychology: Is Free Will Necessary for Moral Responsibility? Mind \& Language, 30, 603-627.

Focquaert, F. (2019). Free Will Skepticism and Criminal Punishment: A Preliminary Ethical Analysis. In D. Pereboom, E. Shaw, \& G. D. Caruso (Eds.), Free Will Skepticism in Law and Society: Challenging Retributive Justice (pp. 207-236). Cambridge: Cambridge University Press.

Gostin, L. O., Gravely, S. D., Shakman, S., Markel, H., \& Cetron, M. (2004). Quarantine: Voluntary or Not? The Journal of Law, Medicine \& Ethics, 32, 83-86.

Hart, H. L. A. (1968). Punishment and Responsibility. Oxford: Clarendon Press.

Husak, D. N. (1992). Why punish the deserving? Noûs, 26, 447-464. JSTOR.

Iacobelli, T. (2013). Death or deliverance: Canadian courts martial in the great war. Vancouver: UBC Press.

Knobler, S., Mahmoud, A., Lemon, S., Mack, A., Sivitz, L., \& Oberholtzer, K. (Ред.). (2004). Learning from SARS: Preparing for the next disease outbreak: workshop summary. Washington, DC: National Academies Press.

Lemos, J. (2016). Moral Concerns About Responsibility Denial and the Quarantine of Violent Criminals. Law and Philosophy, 35, 461-483.

Lemos, J. (2019). A Moral/Pragmatic Defense of Just Deserts Responsibility. Journal of Information Ethics, $28,73$.

List, C. (2019). Why Free Will is real. Cambridge, Massachusetts: Harvard University Press.

Menninger, K. A. (1968). The crime of punishment. New York: Penguin Books. 
Ministry for europe and foreign affairs. (2020, may 22). travel restrictions and implementation of public health measures at borders-press release issued by the ministry of the interior, the ministry for europe and foreign affairs and the ministry for solidarity and health (22 may 2020). retrieved october 2, 2020, from france diplomacy - ministry for europe and foreign affairs website: https://www. diplomatie.gouv.fr/en/coming-to-france/coronavirus-advice-for-foreign-nationals-in-france/coron avirus-statements/article/travel-restrictions-and-implementation-of-public-health-measures-at-borde rs

Moore, M. S. (2010). placing blame: a theory of the criminal law (illustrated edition). Oxford ; New York: Oxford University Press.

Murphy, J. G. (1979). Cruel and unusual punishments. В M. A. Stewart (Ред.), Law, Morality and Rights (cc. 373-404). Dordrecht: Springer Netherlands.

Murphy, J. G. (2007). Legal moralism and retribution revisited. Criminal Law and Philosophy, 1, 5-20.

Mustafa, M., Young, A. (2008). Feud Narratives: Contemporary Deployments of the kanun in Shala Valley, Northern Albania. OpenBU. Retrieved from https://hdl.handle.net/2144/4349

Nick Paton Walsh, Nothing left to lose: grief-crazed murder suspect haunted by family's air deaths, THE GUARDIAN (Feb. 27, 2004, 8:40 PM), https://www.theguardian.com/world/2004/feb/28/russia. lukeharding.

Pereboom, D. (2001). Living without free will. Cambridge. Newyork: Cambridge University Press.

Pereboom, D. (2014a). Free will, agency, and meaning in life. Oxford; New York: Oxford University Press.

Pereboom, D. (2014b). "Respones to John Fischer and Dana Nelkin", Science, Religion, and Culture, 1(3): $218-25$

Pereboom, D. (2017). A Defense of Free Will Skepticism: Replies to Commentaries by Victor Tadros, Saul Smilansky, Michael McKenna, and Alfred R. Mele on Free Will, Agency, and Meaning in Life. Criminal Law and Philosophy, 11, 617-636.

Pereboom, D. (2018). Incapacitation, Reintegration, and Limited General Deterrence. Neuroethics. https://doi.org/10.1007/s12152-018-9382-7

Pereboom, D. (2019). Free will skepticism and prevention of crime. In E. Shaw, D. Pereboom, \& G. D. Caruso (Eds.), Free Will Skepticism in Law and Society (1st ed., pp. 99-115). Cambridge University Press.

Pereboom, D., Caruso, G. D. (2018). Hard-Incompatibilist Existentialism: Neuroscience, Punishment, and Meaning in Life. In G. D. Caruso \& O. Flanagan (Eds.), Neuroexistentialism. New York: Oxford University Press.

Porta, M. S., Greenland, S., Hernán, M., Silva, I. dos S., Last, J. M., \& International Epidemiological Association (Eds.). (2014). A dictionary of epidemiology (Six edition). Oxford: Oxford University Press.

Pundik, A. (2016). Freedom and Generalisation. Oxford Journal of Legal Studies, 37, 189-216.

Quarantine and Isolation I Quarantine I CDC. (2020). Retrieved March 19, 2020, from https://www.cdc. gov/quarantine/index.html

Rawls, J. (1955). Two concepts of rules. The Philosophical Review, 64, 3-32. JSTOR.

Schoeman, F. D. (1979). On Incapacitating the Dangerous. American Philosophical Quarterly, 16, 27-35.

Smilansky, S. (2017). Pereboom on Punishment: Funishment, Innocence, Motivation, and Other Difficulties. Criminal Law and Philosophy, 11, 591-603.

Strawson, G. (2010). Freedom and Belief. Oxford University Press.

Tadros, V. (2011). The Ends of HarmThe Moral Foundations of Criminal Law. Oxford University Press.

Upshur, R. E. G. (2002). Principles for the Justification of Public Health Intervention. Canadian Journal of Public Health, 93, 101-103.

Upshur, R. E. G. (2003). The Ethics of Quarantine. AMA Journal of Ethics, 5.

Vincenzo Mattei, Albania: The dark shadow of tradition and blood feuds, ALJAZEERA (May 14, 2016), https://www.aljazeera.com/features/2016/5/14/albania-the-dark-shadow-of-tradi tion-and-blood-feuds.

von Hirsch, A. (1992). Proportionality in the Philosophy of Punishment. Crime and Justice, 16, 55-98. JSTOR.

Waller, B. N. (2015). The Stubborn System of Moral Responsibility. The MIT Press. JSTOR.

Wegner, D. M. (2002). The illusion of conscious will. Cambridge, Mass.: MIT Press.

White, M. D. (2011). Retributivism. Oxford University Press.

Wood, L. (1938). Responsibility and Punishment. Journal of Criminal Law and Criminology, 28, 630. 
Woodbury, E. N. (1921). Causes for Military Desertion; A Study in Criminal Motives. Journal of the American Institute of Criminal Law and Criminology, 12, 213.

Publisher's Note Springer Nature remains neutral with regard to jurisdictional claims in published maps and institutional affiliations.

\section{Authors and Affiliations}

\section{Sergei Levin ${ }^{1} \cdot$ Mirko Farina $^{2,3}$ (D) Andrea Lavazza ${ }^{4}$}

Sergei Levin

serg.m.levin@gmail.com

Andrea Lavazza

lavazza67@gmail.com

1 National Research University Higher School of Economics, 16 Soyuza Pechatnikov Street, St Petersburg, Russian Federation 190121

2 Faculty of Humanities and Social Sciences, Universitetskaya St,1, Innopolis, Russian Federation 420500

3 Department of Philosophy, Philosophy Building, Strand Campus, King's College, London WC2R 2LS, UK

4 Senior Research Fellow in Neuroethics, Centro Universitario Internazionale, Via Antonio Garbasso 42, 52100 Arezzo, Italy 